\title{
علاقة قلق المستقبل بالدافع بالإنحاز لدى طالبات جامعة الإمام محمد بن سعود الإسلامية بالإن لإنة
}

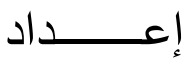 \\ أ/ نشمية سعود صباح العنزي \\ مدربة مهارات في السنة التحضيرية \\ جامعة الملك سعود
}


علاقة قلق المستقبل بالدافع للإنجاز لاى طالبات جامعة الإمام محمد سعود الإسلامية أ/ نشمية سعود صياح العنزي

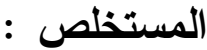

هدفت الدراسة الحالية إلى الكثف عن علاقة القلق التحصيل الدراسي لدى طالبات

السنة التحضرية بجامعة الملك سعود ، وتكونت عينة الدراسة من ( . بَ) طالبة، من الكليات

العلمية والإنسانية، استخدمت الباحثة مقياس القلق لثقير (0 ب)، ومقياس التحصيل الدراسي،

كما تم استخدام بعض الأساليب الإحصائية التي تتطلبها أسئلة البحث ، وفى ضوء ذلك قدمت الدراسة مجموعة من النتائج والتوصيات .

الكلمات المفتاحية : القلق ـ التحصيل ـ الدافعية ـ السنة التحضرية . 
علاقة قلق المستقبل بالدافع للإنجاز لاى طالبات جامعة الإمام محمد سعود الإسلامية

أ/ نشمية سعود صياح الاسلامية العنزي

The relationship between anxiety and academic

achievement among the students of the preparatory year at

King Saud University.

\author{
Nashmia Saud Al-Enezi \\ trained skills in the preparatory year \\ King Saud University
}

\title{
Abstract:
}

The present study aimed at revealing the relationship of anxiety to academic achievement in the students of the preparatory year at King Saud University. The study sample consisted of (300) female students from the scientific and humanities colleges. The researcher used the anxiety scale for Shaker (2005) Some of the statistical methods required by the research questions, in light of which the study presented a set of conclusions and recommendations.

Keywords: anxiety, motivation, achievement, preparatory year. 
يعتبر القلق سمة من سمات هذا العصر فالتطور والثقدم الحضاري والتكنلوجي والتغيرات السريعة المتلاحقة في شتى مناحي الحياه ساهت في جعل الانسان يقف حائرا قلقا

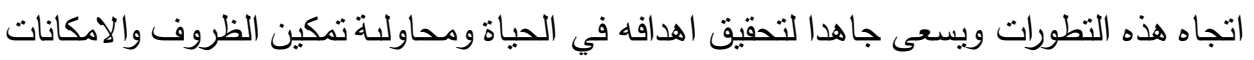
لتحقيق اهدافه فاذا صعب عليه ذلك فانه يشعر بالضيق والاضطراب الذي يقلل من كفاءته ويزيز القلق والثعور بالخطر من مستقبله وانتاجيتهم حيث يظهر نتيجة ظروف الحياة الصعبة والمعقدة

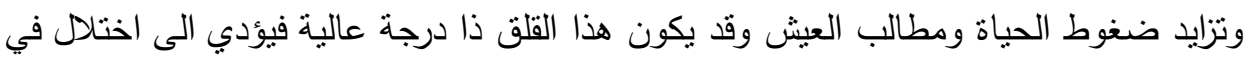

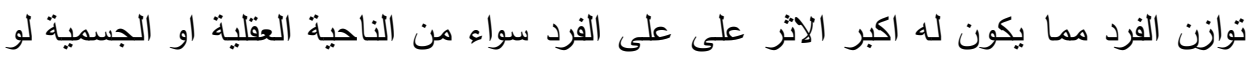

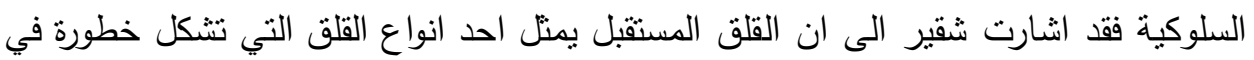
حياة الفرد والتي تمثل خوف من مجهول ينجم عنه خبرات ماضيه وحاضره ايضا يعيشها الفرد تجعله يشعربعدم الامان وتوقع الخطر وعدم الاستقرار وتسبب لديه هذه الحالة (ثقير .زينب

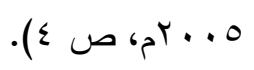

واشتارت سعود ان القلق لدى طلاب وطالبات الجامعه مرتفع ويشكل ظاهرة واضحة لمجتمع مليء بالمتغيرات مشحون بعوامل مثيرة مجهولة المصير تؤدي تفاعلات الاقتصادية

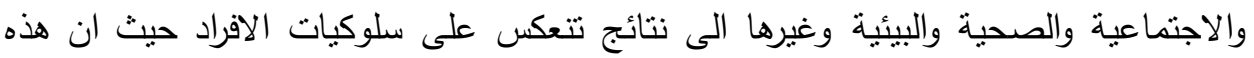

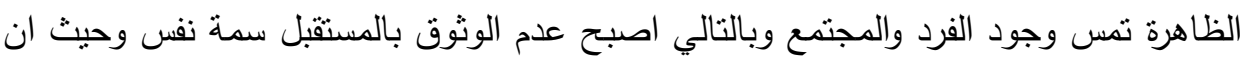

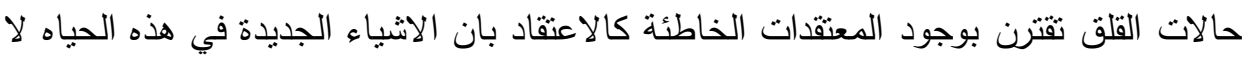

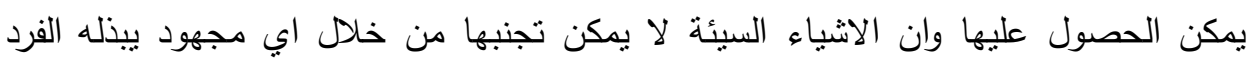

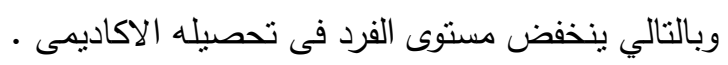

حيث التحصيل الدراسي برتبط بنوعين من المتغيرات الأول ذاتي يتمثل في الذكاء

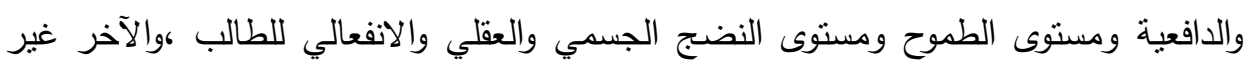

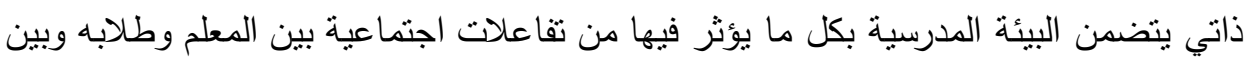
الطلاب بعضهم البعض وطرق تدريس وإمكانات مادية هذا إلى جانب نوافر الأمن النفسي

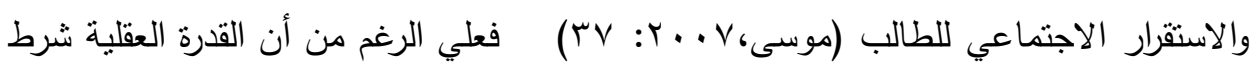

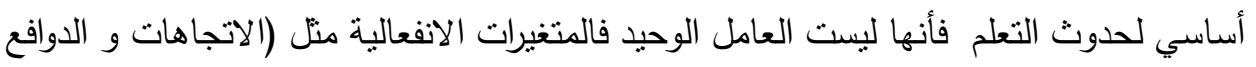

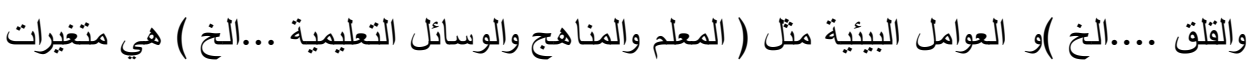
وسيطة تؤثر على عملية التعلم واستجابات الفرد الكمية والكيفية . 
وقياسا على ماسبق ولان الفتاة الجامعية احد عناصر البثرية الاساسية المساهمة في

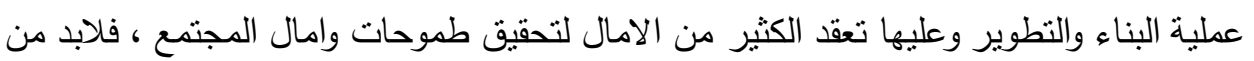

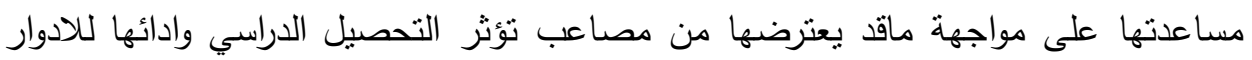
المامونة منها. لذلك جاءت اهية تطبيق هذه الدراسة على الطالبة الجامعية لمعرفة ما يؤنز عللى التحصيل الدراسي

ومن هذا المنطق تحاول الباحثة ان يسهم هذا البحث الذي يتتاوله القلق وعلاقته

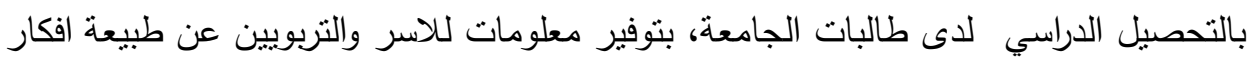
الطالبات التي قد تسبب لهن القلق وتحول دون تحقيق طموحاتهن وتطلعاتهن ، كذلك يمكن ان

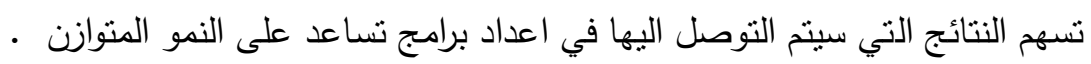
مشكلة الدر اسة أنة

تتعكس خطورة ظاهرة القلق سلبا على للتحصيل الدراسي مما يؤثر على مستقبلهن العلمي

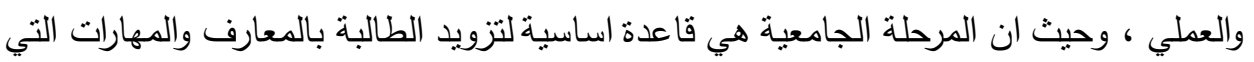

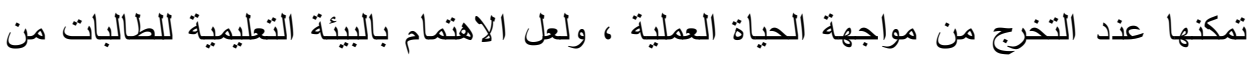

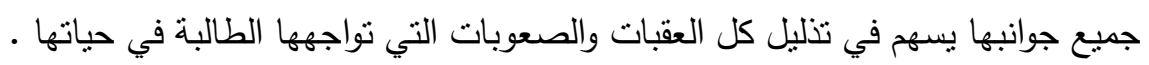

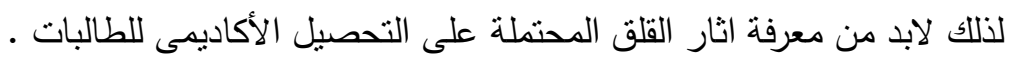
وفي ضوء ما تقدم تكمن اسئلة الدراسة فيما ياتي : 1- ما العلاقة ببين القلق والتحصيل الدراسي لاى طالبات السنة التحضيرية بجامعة الملك بلك سعود ?

$$
\text { ץ- هل توجد فروق دالة احصائية تعزى لمتغير التخصص (علمي - ادبي) ؟ }
$$

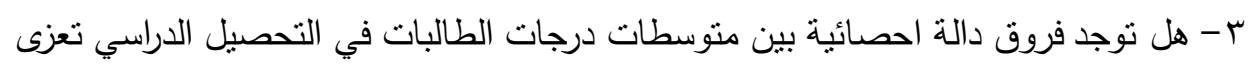

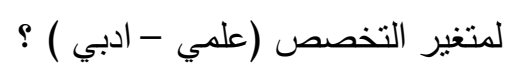

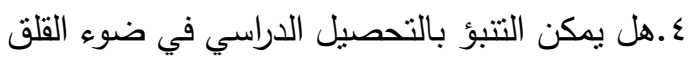
اهداف الدر استة

تسعى الدراسة الحالية الى تحقيق الاهداف التالية :الكثف عن عالقة القلق والتحصيل الدراسي

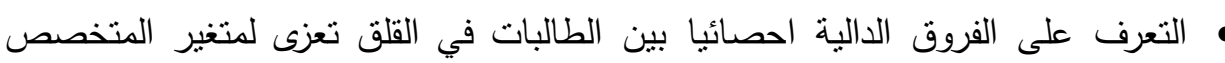

$$
\text { (علمي - ادبي) }
$$

التعرف على الفروق الدالة احصائيا بين الطالبات في التحصيل الدراسي تعزى لمتغير

$$
\text { التخصص ( علمي - ادبي) }
$$




$$
\text { أهمية الدر اسة الأنة }
$$

او الا: الاهمية النظرية : - الاهن

الاهتمام بطالبات الجامعة اللاتي يتحملن مسؤبية النهوض بمجتمعهن وهن في مرحلة مهمة تعد مرحلة البداية في تحمل المسؤولية والتفكير في المستقبل ثانيا : الاهمية التطبيقية : تتصح اهمية الدراسة بارشاد الاباء والمربين حول الضغوط التي نواجه طالبات الجامعة

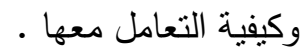

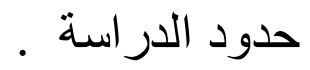

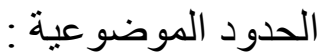

حيث ان موضوع الدراسة الحالية هو : الحدود :

1 القلق وعلاقته بالتحصيل الدراسي لدى طالبات السنة التحضرية بجامعة الملك سعود.

r - الحدود المكانية تتمنل الحدود الرياض، وعلى الكليات العلمية الادبية . ץ-الحدود الزمنية: ترتبط الحدود الزمنية بفترة تطبيق الدراسة وهو الفصل الدراسي الثاني من

تعرف شقير، زينب (0 . . rم، 0) القلق بأنه " خلل او اضطرلااب نفسي المنشا ينجم

عن خبرات ماضية غير سارة، مع تشويه وتحريف ادراكي معرفي للواقع وللذات من خلال

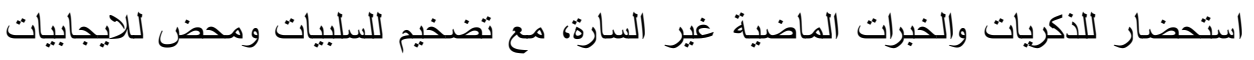
بالذات والواقع، تجعل صاحبها في حالة من التوتر وعدم الامان ، مما قد يدفعه لتدمير الذات

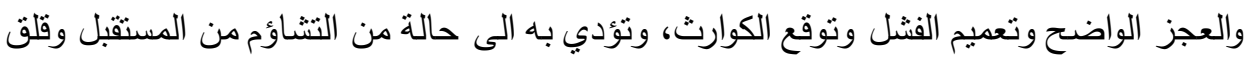
التقكير في المستقبل والخوف من المشكلات الاجتماعية ـ هي الارجة التي تحصل عليها من خلال الروئة المستقبلية المنوقعة، والافكار الوسواسية وقلق الموت والياس.

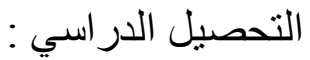

بأنه مدى استيعاب الطالبات لما تعلموه من خبرات معينة في مادة دراسية مقررة ويقاس

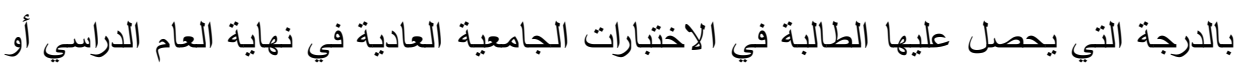

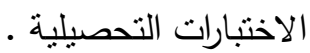


ان المعنى اللغوي لكلمة القلق في المعجم الوسيط بمعنى قلق الثيء اي حركه فلم

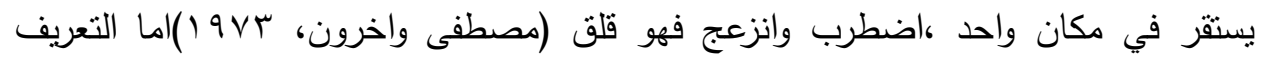

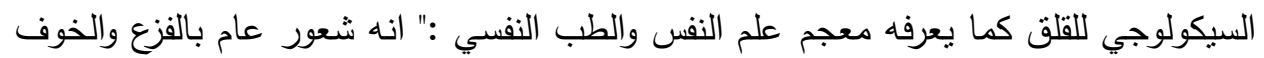
من شر مرتقب وكارثة نوشك ان تحدث،والقلق استجابة لتهديد غير محدد كثيرا ما يصدر عن بن الفرهي صراعات لاشعورية ومشاعر كعدم الامان والنرعات الغريزية الممنوعة المنبعثة من داخل النفس

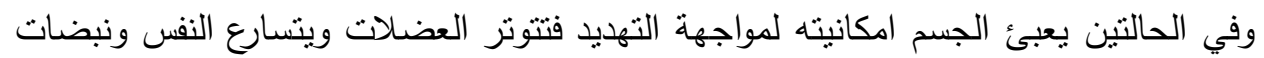

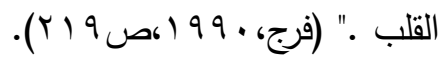

ويعرف ريتشارد .م. سوين ( Richard.m ) القلق بانه : حالة انفعالية غير سارة

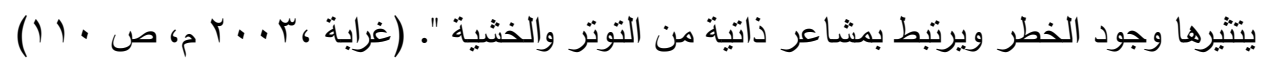

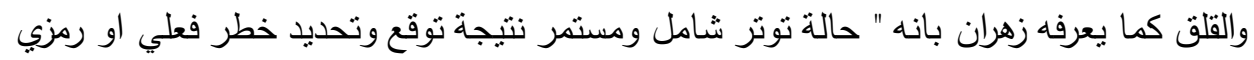

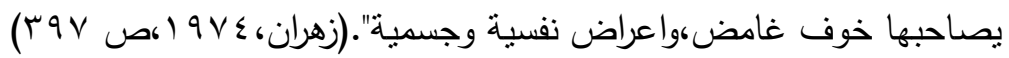

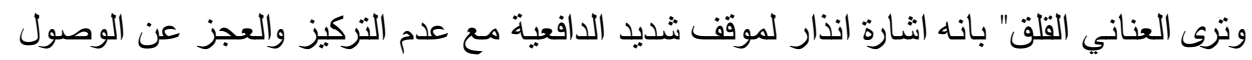

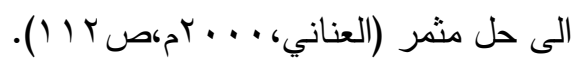

ويظل القلق العصبي هو النوع الذب لا يدرك المصاب به مصدره حيث بت تنتابه حالة من الخوف الغامض غير المبرر كما ان له العديد من الاعراض الني تندو واضحة على الثخص .

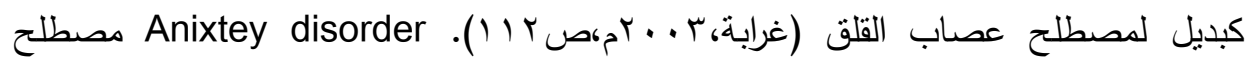
اضطراب النفس القلق. وترى الباحثة مما سبق اختلاف الباحثين في تعريف القلق وتتوع لهربه

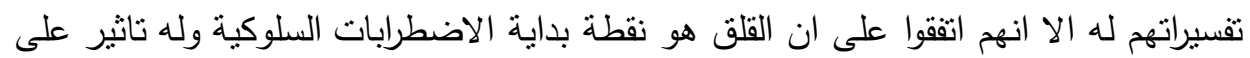
صحة الفرد وانتاجيته. القلق: anxiety

ان الظروف التغير الاجتماعي التي تمر بها المجتمعات البشرية قد تستشير القلق لدى

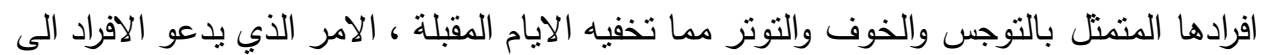
اعادة النظر في مخططاتهم واهدافهم مما ينسجم مع ظروف التغير ، ويبقى التغير الاجتماعي

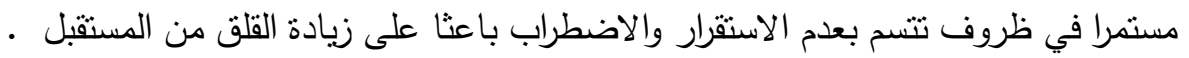

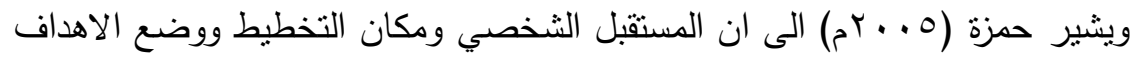
وتحقيقها في هذا المعنى يكون المستقبل الممنل حاليا ادراكيا سوف يلتقي مع المستقبل الحقيقي 
علاقة قلث المستقبل بالدافع للإنجاز لاى طالبات جامعة الإمام محمد سعود الإسلامية أ/ نشمية سعود صياح العنزي

والى اي درجة يكون منظور المستقبل مساحة مفتوحة لعمليات معرفية مختلفة واتجاهات عاطفية اعتمادا على المتوقع ان تمنلئ به هذه المساحة اما احداث اكثر ايجابية او اكثر سلبية.

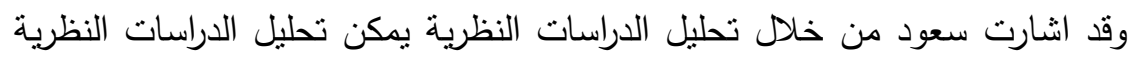

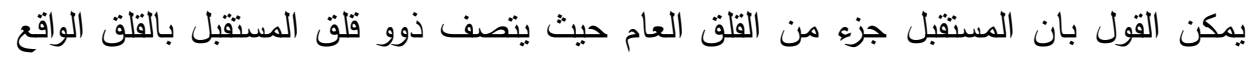
الراهن والمعمم على المستقبل ويتمثل في مجموعة البنى كالتشاؤم، وادراك العجز ، وفقدان

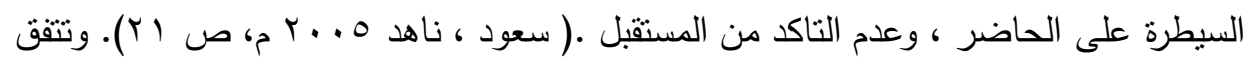

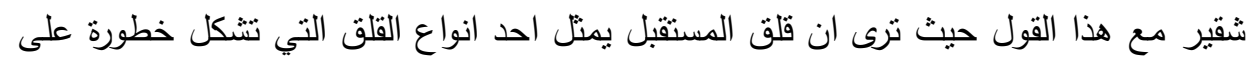

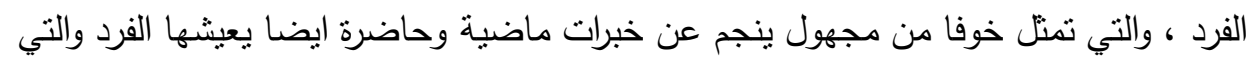

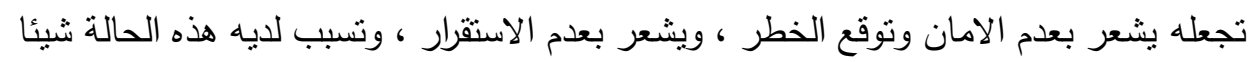

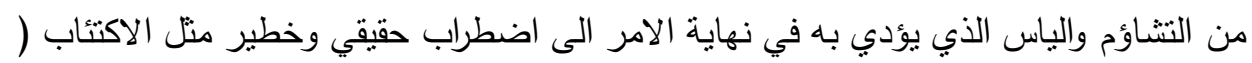

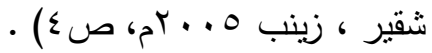

$$
\begin{aligned}
& \text { التحصيل الدر اسي : نئي هـ }
\end{aligned}
$$

يعتبر التحصيل الدراسي موضوعا مهما يعنى به كل المربيين فهو المؤشر على تمكن

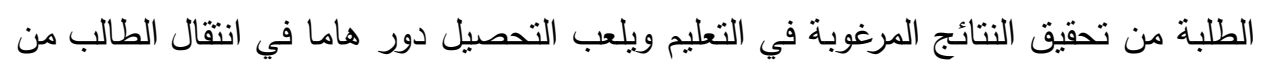
مرحله دراسية إلى أخرى ومن صف إلى آخر وهو المرجع الأساسي بقبول الطلبة في الكليات

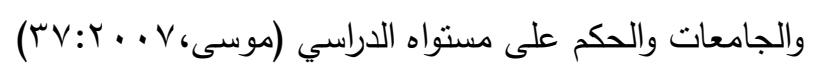

فالتحصيل الدراسي ظاهره معقده تتدخل فيها مجموعه من المتغيرات العقلية وغير العقلية تتفاعل فيما بينهما بحيث يصعب في كثير من الأحيان الفصل بينهما أو تحديد الإسهام

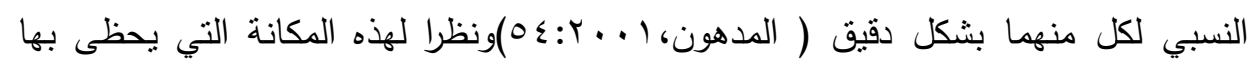
التحصيل الدراسي فقد تعرض له كثير من الباحثين بالدراسة والبحث موضحين جوانبه المختلفة ومحاولين وضع تعريف لهذا المفهوم فقد أثنار أبو حطب إلى أن التحصيل لغة يعنى الانجاز والإجراء وهو مرتبط بآثار مجموعه من الخبرات التي بمكن وصفها بأنها مقننه أو مقصودة

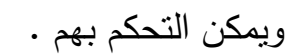
الدر اسة الميدانية النية منهج الدر اسـة: 
علاقة قلث المستقبل بالدافع للإنجاز لاى طالبات جامعة الإمام محمد سعود الإسلامية أ / نشمية سعود سعد صياًح العنزية

أنبعت الباحثة في هذه الدراسة المنهج الوصفي الإرتباطي الذي يهنم بوصف الظاهرة وصفا دقيقا من خلال التعبير النوعي ودراسة العلاقات التي توجد بين هذه الظاهرة المراد دراستها والظواهر الأخرى والتعبير عنها كما وكيفا.

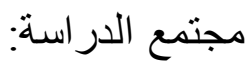

يتألف مجتمع الدراسة الحالية من جميع طالبات السنة التحضيرية بجامعة الملك سعود

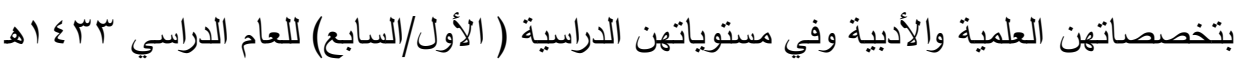

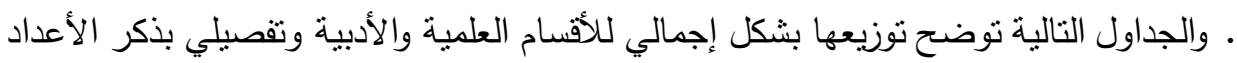

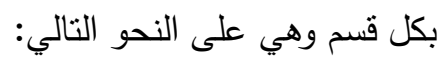

\begin{tabular}{|c|c|c|}
\hline \multicolumn{3}{|c|}{ جدول رقم ( ) نوزيع عينة الدر اسة بشكل إجمالي } \\
\hline العدد & التخصص & السنة الدر اسية \\
\hline Vo & علمي & المستوى الأول \\
\hline Vo & علمي & المستوى السابع \\
\hline vo & أدبي & المستوى الأول \\
\hline vo & أدبي & المستوى السابع \\
\hline
\end{tabular}

جدول رقم (r) يوضح التخصصات التفصيلية للطالبات اللاتي اجبن على مقياس القلق المستقبل

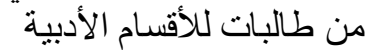

\begin{tabular}{|c|c|c|}
\hline القسم & الكليات الأدبية & التخصص \\
\hline الشريعة & كلية الشريعة & \multirow[t]{7}{*}{ الأدبي } \\
\hline أصول الدين & كلية الدعوة أصول الدين & \\
\hline اللغة العربية & كلية اللغة العربية & \\
\hline علم النفس & \multirow[t]{4}{*}{ كلية العلوم الاجتماعية } & \\
\hline علم الاجتماع & & \\
\hline التاريخ & & \\
\hline الجغرافيا & & \\
\hline
\end{tabular}

جدول رقم (T) يوضح التخصصات التفصيلية للطالبات اللاتي اجبن على مقياس القلق من التصني طالبات المستوى الأول للأقسام العلمية 
علاقة قلث المستقبل بالدافع للإنجاز لاى طالبات جامعة الإمام محمد سعود الإسلامية أ/ نشمية سعود صياح العنزية لأسيامي

\begin{tabular}{|c|c|c|}
\hline القسم & الكليات العلمبة & التخصص \\
\hline الرياضيات & \multirow[t]{3}{*}{ كلية العلوم } & \multirow[t]{5}{*}{ العلمي } \\
\hline الفيزياء & & \\
\hline الكيمباء & & \\
\hline علوم الحاسب & \multirow{2}{*}{ كلية علوم الحاسب ونظم } & \\
\hline نظم المعلومات & & \\
\hline
\end{tabular}

* لا توجد أقسام علمية في المستوى الدراسي السابع عدا كلية علوم الحاسب ونظم المعلومات.

$$
\begin{aligned}
& \text { ـ أدو ات الدر اسـة. } \\
& \text { استخدمت الباحثة الأدوات التالية: } \\
& \text { مقياس القلق أعداد أ.د شقير (0. . . بم) } \\
& \text { وفيما يلي عرض لهذه الأدوات: } \\
& \text { - مقباس القلق: }
\end{aligned}
$$

وصف مقياس القلق:أعد هذا المقياس زينب محمود شقير (0 . . rم)، ويهدف إلى معرفة رأي الفرد الشخصي بوضوح وذلك على مقياس متدرج من معترض بشدة (لا) معترض أحيانا (قليلا)، بدرجة منوسطة،عادة (كثيرا)، دائما (تماما) وموضوع أمام هذه التقديرات خمس معس معنس درجات هي (ع -r-r-1- صفر) على الترتيب وذللك عندما يكون اتجاه البنود نحو القلق سلبي، بينما تكون هذه التقديرات في اتجاه عكسي (صفر - 1-r-r- - ع) عندما يكون اتجاه التقديرات نحو القلق ايجابي، وبذلك تشير الدرجة المرتفعة على المقياس إلى ارتفاع القلق لدى الفرد.

ويتكون المقياس من (Y^) مفردة موزعة على خمسة محاور كالآتي:

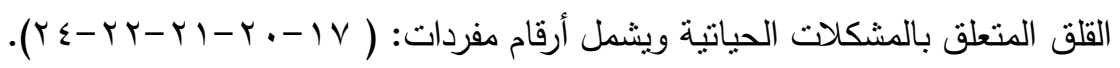

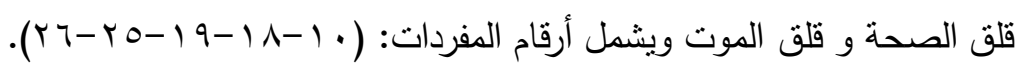

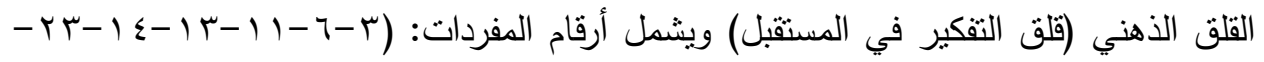
.$(r \wedge$

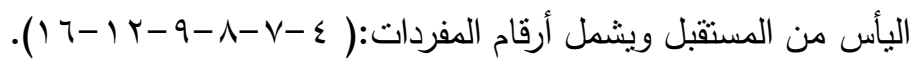

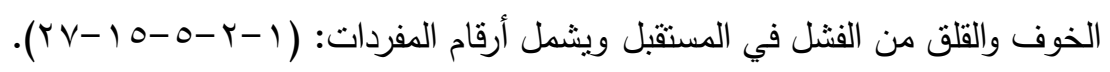


علاقة قلث المستقبل بالدافع للإنجاز لاى طالبات جامعة الإمام محمد سعود الإسلامية أ/ نشمية سعود صياح الاسلامية العنزي

تصحيح مقياس قلق المستقبل:تتراوح الدرجة الكلية للمقياس مابين (صفر - r با درجة)، ويتم تحديد المستويات طبقا الجدول الآتي: جدول رقم (ع ) الدرجة الكلية لمقياس قلق المستقبل ومستوياته

\begin{tabular}{|c|c|c|c|}
\hline \multicolumn{2}{|c|}{ مستويات قلق المستقبل } & اتجاه التصحيح & أرقام البنود \\
\hline من |q-1|| درجة & القلق مرتفع جدا (شديد) & \multirow[t]{2}{*}{ ع -r-r-1 - صفر } & \multirow[t]{2}{*}{ من 1-. } \\
\hline من ^^ - 9 درجة & القلق مرتفع & & \\
\hline من 0؟ -VT درجة & القلق معتدل (متوسط) & \multirow[t]{4}{*}{ صفر -1-Y-r-Y- } & \multirow[t]{4}{*}{ من ||-11 } \\
\hline من r & القلق بسيط & & \\
\hline من صفر - اب درجة & القلق منخفض & & \\
\hline صفر -r|| درجة & الدرجة الكلية للقلق & & \\
\hline
\end{tabular}

صدق مقياس القلق: قامت معدة المقياس. شقير (0. 두) بحساب الصدق للمقياس بالطرق

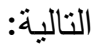

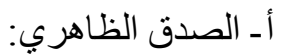

حيث تم عرض المقياس خلال فترة إعداده على مجموعة من المختصين في مجال الصحة النفسية والإرشاد النفسي. بـ صدق المحك ( الصدق التناد النفيبي):

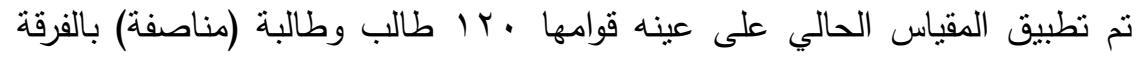
الرابعة بكلية التربية بجامعة طنطا ضمن (عينه التقنين) كما طبق مقياس القلق إعداد عبدالفتاح

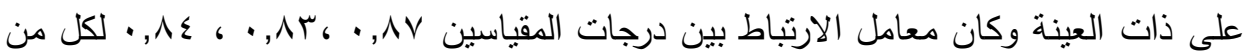

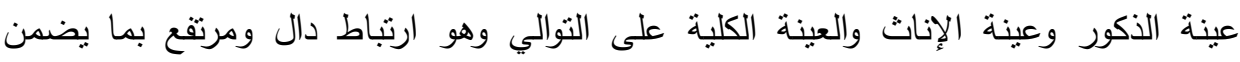
صلاحية المقياس للاستخدام. ج- صدق المفردات ( صدق التكوين) : حيث تم حساب ارتباط كل بند بالدرجة الكلية للمقياس وذلك على عينة طلاب وطالبات

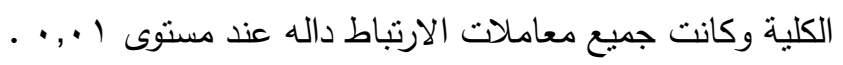

$$
\begin{aligned}
& \text { دـ طريقة الاتساق الداخلي ( صدق التكوين): }
\end{aligned}
$$

حيث حساب معاملات الارتباط بين محاور المقياس الخمس وبين بعضهم البعض النصاف

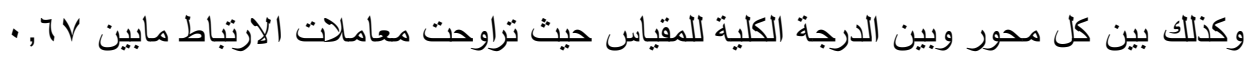

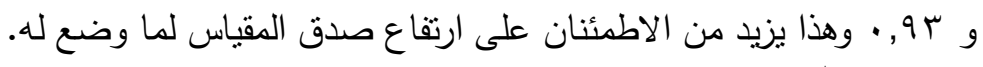

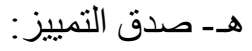


علاقة قلق المستقبل بالدافع للإنجاز لدى طالبات جامعة الإمام محمد سعود الإسلامية أ / نشمية سعود سعد صياًح العنزية

يوضتح إمكانية استخدام مقياس قلق المستقبل في الكثف عن الفروق بين المجموعات المختلفة في درجة القلق واستخدم اختبار "ت" للفروق بين الفئات ،وكانت قيمة "ت" دالة عند مستوى 1 ., • أي أن هناك فروق ذات دلالة إحصائية بين المجموعات الثنائية المختلفة التي توصلت إلى إن المقياس لديه القدرة على التمبيز بين فئات مختلفة مما يطمئن على صدقه وإمكانية استخدامه في القياس. ثبات مقياس القلق: قامت معدة المقياس ـ شقير (0 . . r م) بحساب الثبات للمقياس . الصدق والثبات لمقياس القلق في الدراسة الحالية: أ أ- صدق المقياس:

قامت الباحثة بحساب الاتساق الداخلي لمفردات المقياس، وذللك لدى العينة الاستطلاعية، حيث تم حساب معامل الارتباط بين كل عبارة والمجموع الكلي بعد حذف المفردة، والجدول التالي يوضح الاتساق الداخلي للمقياس

جدول رقم (0) معامل الارتباط بين درجة المفردة والمجموع الكلي للمقياس بعد حذف المفردة

\begin{tabular}{|c|c|c|}
\hline الارتباط معامل & العبــــــــــارة & r \\
\hline $.325^{*}$ & أؤمن بالقضاء والقدر ، وان القدر يحمل أخبارا سارة في المستقبل. & 1 \\
\hline $.325^{*}$ & التفوق يدفعني دائما لمزيد من التفوق وأكافح لتحقيق مستقبل باهر . & $r$ \\
\hline .044 & تراودني فكرة أنني قد أصبح شخصا عظيما في المستقبل. & r \\
\hline $.532^{* *}$ & لنفسي، واعرف طمحات وأهداف واضحة في الحياة، واعمل لمستقبلي وفقا لخطة رسمتها & $\varepsilon$ \\
\hline$-.082-$ & الالتزام الديني والأخلاقي والتمسك بمبادئ معينة يضمن للإنسان مستقبل آمن. & 。 \\
\hline$-.054-$ & الأفضل أن تعمل لدنياك كأنك تعيش أبدا وتعمل لآخرتلك كأنك تموت غداً. & Y \\
\hline $.666^{* *}$ & أشعر أن الغد (المستقبل) سيكون يوما ما مشرقاً، وستحقق آمالي في الحياة. & V \\
\hline $.469 * *$ & أملي في الحياة كبير لأن طول العمر يبلغ الأمل & $\wedge$ \\
\hline $.585^{* * *}$ & يخبئ الزمن مفاجآت سارة،ولا يأس في الحياة ولا حياة مع اليأس. & 9 \\
\hline $.302^{*}$ & حياتي مملوءة بالحيوية والنشاط والرغبة في تحقيق الآمال. & 1. \\
\hline .211 & المنلكني الخوف والقلق والحيرة عندما أفكر في المستقبل وأنه لاحول لي ولا قوة في & 11 \\
\hline
\end{tabular}


علاقة قلث المستقبل بالدافع للإنجاز لاى طالبات جامعة الإمام محمد سعود الإسلامية أ/ نشمية سعود صياح الاسلامية العنزي

\begin{tabular}{|c|c|c|}
\hline الارتباط معامل & العبــــــــــارة & r \\
\hline $.398 *$ & يدفعني الفثل إلى اليأس وفقدان الأمل في تحقيق مستقبل أفضل. & Ir \\
\hline $.521^{* * *}$ & أنا من الذين يؤمنون بالحظ ويتحركون على أساسه. & r \\
\hline $.342 *$ & تمشي زي ما تمشي طريقة للتعايش مع الحياة هو عدم التفكير في المستقبل، واترك الحياة & $1 \varepsilon$ \\
\hline $.667 * *$ & تمضي الحياة بشكل مزيف ومحزن ومخيف مما يجعلني اقلق وأخاف من المجهول & 10 \\
\hline $.603 * *$ & مستقبلا أشعر بالفراغ واليأس وفقدان الأمل في الحياة وانه من الصعب إمكانية تحسنها & 17 \\
\hline $.783^{* *}$ & أشعر بالانزعاج لاحتمال وقوع كارثة قريبا بسبب كثرة الحوادث هذه الأيام & IV \\
\hline $.597 * *$ & أشعر بتغيرات مستمرة في مظهري( شكلي) تجعلني أخاف أن أكون غير جذاب ( أنقام الاخرين مستقبلا. & 11 \\
\hline $.826 * *$ & وقتتابني شعور بالخوف والوهم من إصابتي بمرض خطير (أو حادث) في أي & 19 \\
\hline $.289^{*}$ & الحياة المملوءة بالعنف والإجرام تجعل الفرد ينوقع الخطر لنفسه في أي وقت & $r$. \\
\hline $.391 *$ & كثرة البطالة في المجتمع يهدد بحياة صعبة وسوء التوافق الزواجي مستقبلاً & rI \\
\hline $.578 * *$ & غلاء المعيشة وانخفاض الدخل وانخفاض العائد المادي يقلقني على مستقبلي. & rr \\
\hline $.628 * *$ & المستقبل غامض ومبهم ( مجهول) لدرجة تجعل من الصعب ( من العبث) أن & r \\
\hline $.352^{*}$ & ضأكون في أحسن الحياة تجعل من الصعب أن أظل محتفظا بأملي في الحياة وأتفاعل بأنني & $r \varepsilon$ \\
\hline $.497 * *$ & أشعر بالقلق الشديد عندما أتخيل إصابتي في حادث (أو حدث لي بالفعل)(أو & ro \\
\hline $.495 * *$ & يغلب علي تفكير الموت في اقرب وقت خاصة عندما أصاب بمرض ( أو يصاب & Tr \\
\hline **. 517 & أنا غير راض عن مستوى معيشتي بوجه عام مما بشعرني بالفشل في المستقبل. & TV \\
\hline .188 & أشعر أن الحياة عقيمة بلا هدف ولا معنى ولا مستقبل واضح. & rᄉ \\
\hline
\end{tabular}

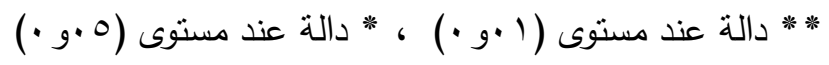


علاقة قلث المستقبل بالدافع للإنجاز لاى طالبات جامعة الإمام محمد سعود الإسلامية أ/ نشمية سعود صياح العنزي

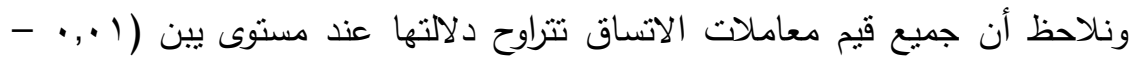

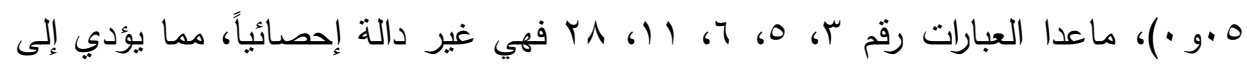

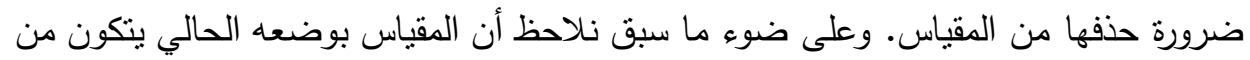

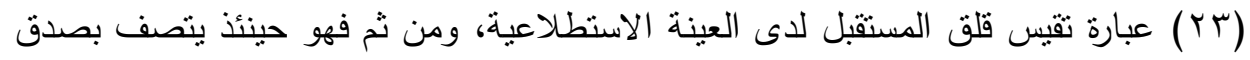

كما قامت الباحثة بحساب معامل الارتباط بين محاور المقياس الخمسة بالمجموع الكلى لها وققاً لا (Tr) عبارة المكونة للمقياس في عباراته الجديدة بعد التقنين، وقد اتضح أن جميعها ذات دلالة عند مستوى ( ( .و •)، مما يدل على صدق مناسب للمقياس، والجدول التالي يوضح ذلك.

\begin{tabular}{|c|c|c|c|c|c|c|}
\hline الخَامس & الر ابع & الثالث & الثثاني & الأول & إرتباط & معال \\
\hline & & & & - & الأول & \multirow{6}{*}{ المحور } \\
\hline & & & - & $.687 *$ & الثاني & \\
\hline & & - & .641 ** & $.601^{* * *}$ & الثالث & \\
\hline & - & $.556 * *$ & .590 *** & .545 & الرابع & \\
\hline - & $.732^{* * *}$ & $.431 \% *$ & $.570 * *$ & $.493 * *$ & الخامس & \\
\hline .765 ** & .830 \%* & $.774^{*}$ & $.874 *$ & $.834 * *$ & المجموع & \\
\hline
\end{tabular}

( )* دالة عند مستوى (1 (•و •).

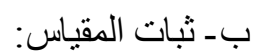

قامت الباحثة بحساب معامل ثبات ألفا كرنباك وذللك للمقياس الذي يتكون من (r ( ب) عبارة، وذللك على ( • ع) طالبة واللاتي يمثلون العينة الاستطلاعية، وقد بلغت قيمة معامل الثبات (1 ( 9 • ) وهذا يدل على ثبات مناسب للمقياس.

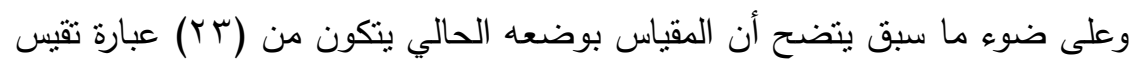
قلق المستقبل بدرجة مناسبة من الصدق والثبات.

$$
\text { - فرضيات الدر اسة: }
$$

ا ـ توجد علاقة دالة بين القلق والتحصيل الدراسي لدى طالبات السنة التحضيرية بجامعة الملك 
علاقة قلث المستقبل بالدافع للإنجاز لاى طالبات جامعة الإمام محمد سعود الإسلامية أ / نشمية سعود سعد صياًح العنزية

r ـ توجد فروق دالة بين متوسطات درجات الطالبات في القلق تعزى لمتغير التخصص. r. توجد فروق دالة بين متوسطات درجات الطالبات في التحصبل الدراسي تعزى لمتغير التخصص. ع. يمكن التتبؤ بالتحصيل الدراسي في ضوء القلق • - نتائج الدراسة: - مان النتائج المتعلقة بالفرض الأول: والذي ينص على " توجد علاقة دالة بين القلق والتحصيل الدراسي لدى طالبات السنة التحضيرية بجامعة الملك سعود " .

\begin{tabular}{|c|c|c|c|c|}
\hline معامل الارتباط & الانحيار افي & المتوسط & ن & المتغير ات \\
\hline \multirow{2}{*}{$-* * r q, \cdot$} & $.0,1 T$ & $0 \leqslant, Y q$ & \multirow[t]{2}{*}{ r.. } & القلق \\
\hline & $\Lambda 0, V$ & $V Y, V Y$ & & التحصيل الدراسي \\
\hline
\end{tabular}

دال عند مستوى (1 (..). (-). يتضح من الجدول أن قيمة معامل ارتباط بيرسون هي (-9 ( • )، وهي قيمة سالبة وذات دلالة إحصائية عند مستوى (1 ...)، ما يعني وجود علاقة ارتباطية سالبة بين القلق والتحصيل الدراسي لاى طالبات السنة التحضرية بجامعة الملك سعود ، وهذا يثير إلى انه كلما زاد قلق المستقبل انخفض التحصيل الدراسي لدى الطالبات. ويتفق هذا مع دراسة عشري

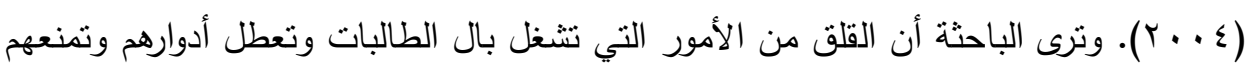
من اتخاذ فلسفة واقعية في الحياة، وعدم القدرة على صياغة أهداف واضحة . كما أن النظرة إلى المستقبل تؤثر على مستوى التحصيل تبعا لما يمنلك الفرد من تقاؤل وبصيرة. النتائج المتعلقة بالفرض الثاني: والذي ينص على " توجد فروق دالة بين منتسطات درجات الطالبات في القلق تعزى لمتغير التخصص".

في الدرجة الكلية للقلق وأبعاده المختلفة كما بوضبار (ت)، لبيان الفروق بين مجموعتي التخصص (علمي - أدبي) 
علاقة قلث المستقبل بالدافع للإنجاز لاى طالبات جامعة الإمام محمد سعود الإسلامية أ/ نشمية سعود صياًح العنزية

جدول (^) اختبار (ت) لبيان الفروق بين مجمو عتي التخصص (علمي - أدبي) في الدرجة الكلية للقلق و أبعاده ألمختلفة.

\begin{tabular}{|c|c|c|c|c|c|c|}
\hline مستوى الدلالة & قيمة ت & الحرية & المنوسط & ن ن & التخصص & المتغير ات \\
\hline \multirow{2}{*}{ غير دالة } & \multirow{2}{*}{$\leq 1,1$} & \multirow{2}{*}{ rqA } & $\neg \cdot, r$ & 10. & العلمي (Y) & \multirow{2}{*}{ لقلق الدستقبل الكلية } \\
\hline & & & $\varepsilon V, Y \wedge$ & 10. & الأدبي (') & \\
\hline \multirow{2}{*}{ غير ةذاد } & \multirow{2}{*}{$r \mid 0,1$} & \multirow{2}{*}{ rqA } & Torr, & 10. & العلمي (Y) & \multirow{2}{*}{ عبلاد لو لأا } \\
\hline & & & $\uparrow \wedge \cdots, \wedge$ & 10. & الأدبي (1) & \\
\hline \multirow{2}{*}{ غير ةذاد } & \multirow{2}{*}{$-Y r \cdot}$, & \multirow{2}{*}{ rqu } & $\wedge \ldots, \uparrow$ & 10. & العلمي (Y) & \multirow{2}{*}{ عبلاد اتثاني } \\
\hline & & & $v \cdots, r$ & 10. & الأدبي (1) & \\
\hline \multirow{2}{*}{ غير ةتلاد } & \multirow{2}{*}{$\wedge 99,1$} & \multirow{2}{*}{ r91 } & $\varepsilon \varepsilon \ldots, \varepsilon$ & 10. & العلمي (Y) & \multirow{2}{*}{ البعد الثالث } \\
\hline & & & $\Lambda \varepsilon \ldots, r$ & 10. & الأدبي (') & \\
\hline \multirow{2}{*}{ غير ةقاد } & \multirow{2}{*}{$v \cdot 9,1$} & \multirow{2}{*}{ rq^ } & VIrr, & 10. & العلمي (r) & \multirow{2}{*}{ عبلاد لارعبا } \\
\hline & & & $91 \ldots, 0$ & 10. & الأدبي (1) & \\
\hline \multirow{2}{*}{ غير تَلاد } & \multirow{2}{*}{$-\vee \wedge \wedge}$, & \multirow{2}{*}{$r q \wedge$} & $v \cdots, r$ & 10. & العلمي (Y) & \multirow{2}{*}{ البعد الخامس } \\
\hline & & & $\varepsilon \varepsilon T V, r$ & 10. & الأدبي (1) & \\
\hline
\end{tabular}

يتضح من الجدول عدم وجود فروق دالة بين التخصص العلمي والأدبي في الدرجة الدادي

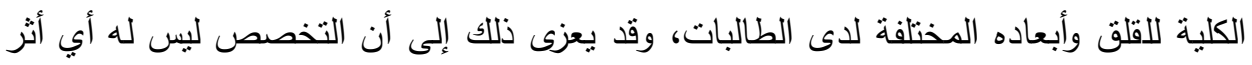
على تشكيل حالة القلق لاى الطالبات.

وهذه النتيجة قد لا تكون ممانلة لغالبية الدراسات التي أثنتت وجود فروق لصالح أحد

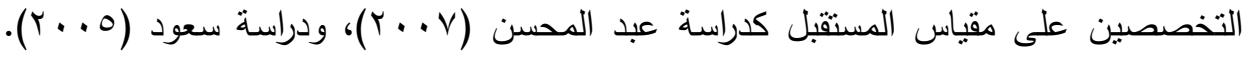

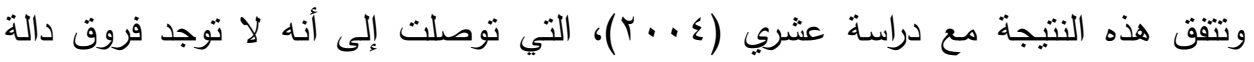
إحصائية بين التخصصات العلمية والأدبية.

وترى الباحثة أن القلق لاى جميع الطالبات لا يتوقف عند حد التخصص، لادبه بل تكثر وتتعدد أسبابه لذلك من الضروري اهتمام المؤسسات التربوية بمناقثنة مشاكل مستقبل الفئة

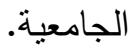
النتائج المتعلقة بالفرض الثالث : والذي ينص على " توجد فروق دالة بين متوسطات درجات الطالبات في التحصيل الدراسي تعزى لمتغير التخصص (علمي، أدبي). 
علاقة قلث المستقبل بالدافع للإنجاز لاى طالبات جامعة الإمام محمد سعود الإسلامية أ/ نشمية سعود صياح العنزية

للتحقق من هذا الفرض تم استخدام اختبار (ت)، لبيان الفروق بين المستويين (الأول - السابع)،

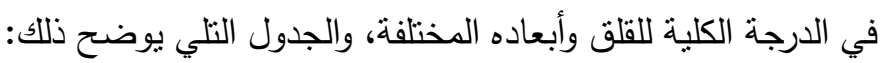
جدول (9) اختبار (ت)، للفروق بين الدرجة الكلية للقلق وأبعاده المختلفة

\begin{tabular}{|c|c|c|c|c|c|c|}
\hline الدلالة & ت & درجات الحرية & ط ط & ن & التخصص & المتغيرات \\
\hline \multirow{2}{*}{ غير دالة } & \multirow{2}{*}{$9 \leqslant 1, \cdot$} & \multirow{2}{*}{ r৭1 } & $r \cdot, V Y$ & 10. & العلمي 1 & \multirow{2}{*}{ التحصيل الدراسي } \\
\hline & & & $10, \mathrm{VT}$ & 10. & الأدبي r & \\
\hline
\end{tabular}

يظهر من الجدول عدم وجود فروق دالة بين التخصص العلمي والأدبي في التحصيل

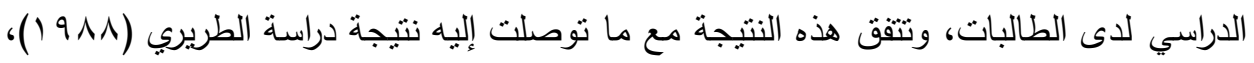

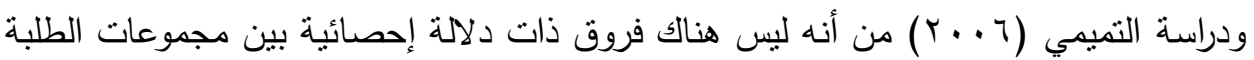
ذوي التخصصات المختلفة في التحصيل الدراسي. ويعزى ذلك إلى أن التخصص ليس لهنه له دور

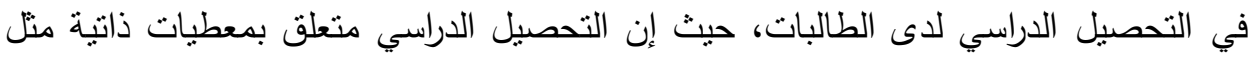

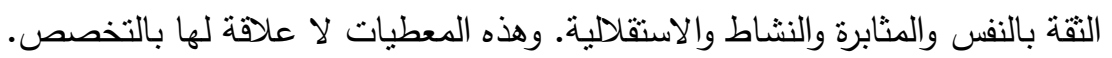

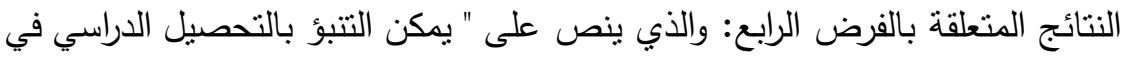

$$
\text { ضوء القلق ". }
$$

للتحقق من هذا الفرض تم استخدام تحليل الانحدار البسيط باعتبار القلق هو المتعير المستقل

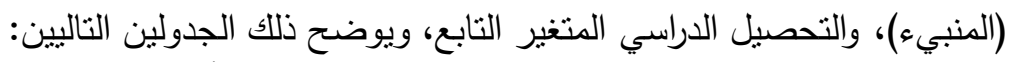

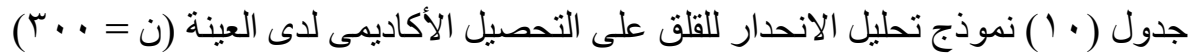

\begin{tabular}{|c|c|c|c|c|c|}
\hline الدلالة & قيمة ف & المربعات & الحرجية & المربعات & النموذج \\
\hline \multirow[t]{3}{*}{$\cdots 1$, } & VYY,OY & $0 \backslash \Lambda, Y \wedge Y$. & 1 & $0 \backslash \wedge, Y \wedge Y$. & لامنغرا \\
\hline & & \&Or,OY & r91 & . & بلاويقا \\
\hline & & & ५११ & $0 \wedge \vee, 1 \wedge \leq 01$ & المجموع \\
\hline
\end{tabular}

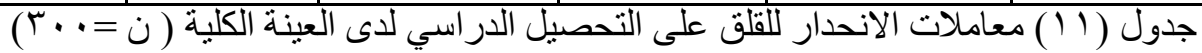

\begin{tabular}{|c|c|c|c|c|}
\hline الدلالة & قيمة ت & الخطأ المعيارى & الانحدار المعبارى معامل ( قيمة & المتغير \\
\hline$\cdot 1, \cdot$ & $917, \vee 74$ & . r & $\uparrow \vee \neg, \vee q$ & باثت \\
\hline$\ldots 1$, & VTr, & $\cdot r r, \cdot$ & -YTO,. & لقلاق \\
\hline
\end{tabular}

يتضح من الجدول السابق أنه يمكن بناء معامل التنبؤ بالصيغة التالية: درجة التحصيل الدراسي= ( 
ويعني هذا أن زيادة القلق بمقدار V9.7V يؤدي إلى زيادة التحصيل الدراسي بمقدار

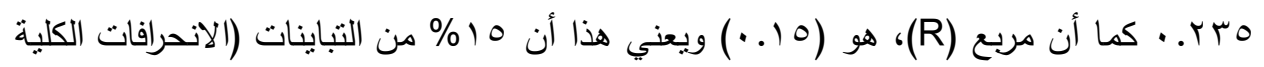

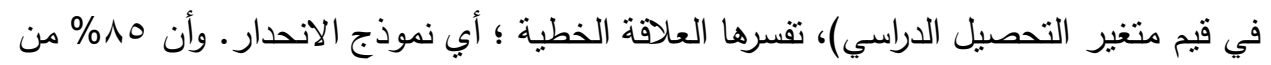

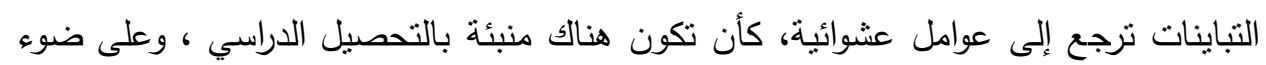

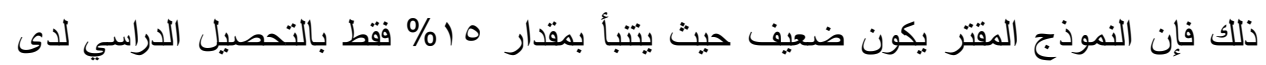

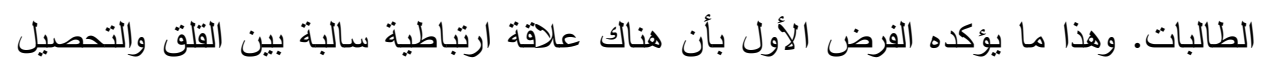
الدراسي.

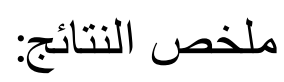
ا. وجود علاقة ارتباطية سالبة بين القلق والتحصيل الدراسي لاى طالبات السنة التحضيرية بجامعة الملك سعود. r. لا توجد فروق دالة بين منوسطات درجات الطالبات في القلق تعزى للتخصص (علمي r. لا توجد فروق دالة بين متوسطات درجات الطالبات في التحصيل الدراسي تعزى للتخصص (التص

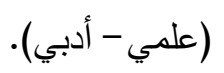

ع. يمكن التتبؤ بالتحصيل الدراسي في ضوء المستقبل بنسبة ضعيفة تمتل 0 10.

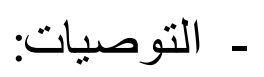

في ضوء النتائج التي توصلت إليها الدراسة الحالية حول القلق وعلاقته بالتحصيل الدراسي لدى

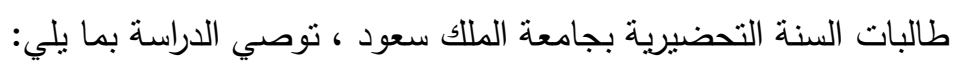
ا ـ الاهتمام بالبرامج التي تعنى بخفض مستوى القلق لادى الطالبات بالمراحل المختلفة.

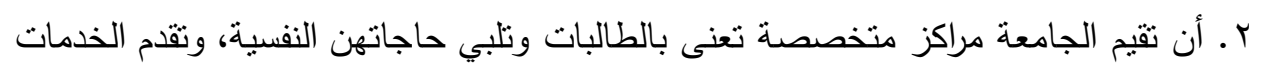
الإرشادية بصورة تساعدهن على التوافق مع الواقع.

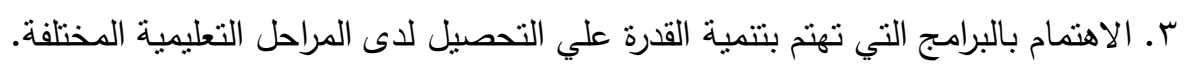

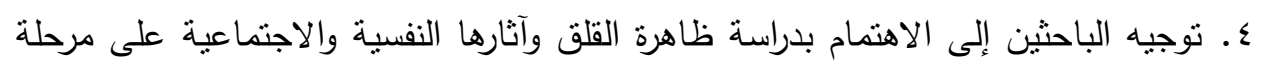
الثباب. هـ الاهتمام بتوجيه الطالبات نحو التخصصات التي نواكب التغيرات السريعة والهتلاحقة على مجالات الحياة المختلفة، والتي تتوافق مع احتياجات سوق العمل. 
علاقة قلث المستقبل بالدافع للإنجاز لدى طالبات جامعة الإمام محمد سعود الإسلامية أ/ نشمية سعود سعدو الإسلاية العنزي

7 ـ إقامة الندوات والمحاضرات وفتح قنوات الحوار مع مرحلة الثباب من أجل نوعيتهم، ووقايتهم

$$
\text { من الاضطرابات النفسية. }
$$

$$
\text { الدر اسات المقترحة: }
$$

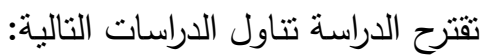

1. إجراء دراسات حول القلق وعلاقته بكل من التفاؤل والتشاؤم والرضا عن الحياة.

r الالتزام الديني وعلاقته بالقلق ومستوى الطموح.

r. دراسة العلاقة بين القلق وكل من المستوى الاجتماعي والاقتصادي وبعض السمات الثخصية لاى طلبة المرحلة الجامعية. 


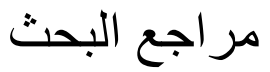

المدهون ، عبد الكريم سعيد (1 ( . ( ). دراسة بعض أساليب التنشئة الاجتماعية وعلاقتها بسمات الشخصية والتحصيل الدراسي •رسالة ماجستير غير منشورة. كلية التربية،جامعة عين

شمس

عبد الخالق ، احمد ، والنيال ، مايسه (1991 ) ) الدافع بالانجاز وعلاقته بالقلق والانبساطدراسات نفسية، ك، اج، عص ص Vrr_ به 7مصر رابطة الاخصائيين النفسيين المصرية. عبد الرحمن ،محمد السيد .9 (9 (م). نظريات الشخصية ـ القاهرة ،دار قباء للطباعة والنشر •

عبد المحسن،مصطفى.(v . . r r). فعالية الارشاد النفسي في خفض قلق المستقبل المهني لدى طلاب كلية التربية في اسيوط.رسالة ماجستير غير منشورة جامعة اسيوط، اسيوط عثمان ، فاروق السيد.(1 . . rم). القلق وادارة الضغوط النفسية ـ القاهرة :دار الفكر العربي. عشري،محمود محي الدين(ع . . r م). قلق المستقبل وعلاقته ببعض المتغيرات الثقافية .دراسة حضارية مقارنة بين طلاب بعض كليات التربية بمصر وسلطنة عمان ، المؤتمر السنوي الحادي عشر للارشاد النفسي بجامعة عين شمس،المجبد الاول. غرابة،ايهاب محمد حسن (r . rم). فاعلية برنامج عقلاني انفعالي في درجة قوة لانا وخفض حدة القلق لدى عينة من المراهقين.رسالة دكتوراة غير منشورة .جامعة عين شمس، القاهرة.

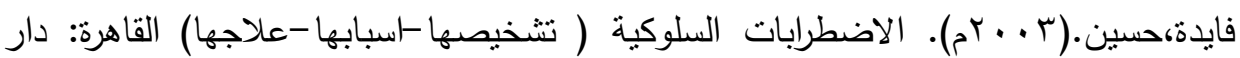
طيبة للنشر والتوزيع.

فرج، عبد القادر .( •99 (م). معجم علم النفس والتحليل النفسي، بيروت: دار النهضة العربية. كفافي ،علاء الدين ( •99 (م). الارشاد والعلاج النفسي الاسري ( المنظور النسقي الاتصالي) . القاهرة، دار الفكر العربي. مسعود، سناء منير (T · . r r). بعض المتغيرات المرتبطة بقلق المستقبل لدى عينة من المراهقين رسالة دكتوراه غير منثورة جامعة طنطا.

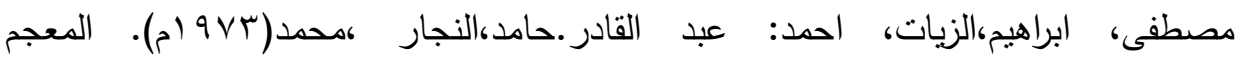
الوسيطز (ط r) طץ. القاهرة : دار المعارف. مندوة، محمود(T . rم). قلق المستقبل وعلاقته ببعض مظاهر التوافق الدراسي لدى طلاب الجمعية المصرية للاراسات النفسية، جامعة عين شمس، العدد 7 ا. 


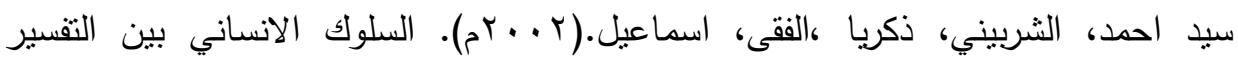
الاسلامي واسس علم لنفس المعاصر . القاهرة. مكتبة الانجلو المصرية.

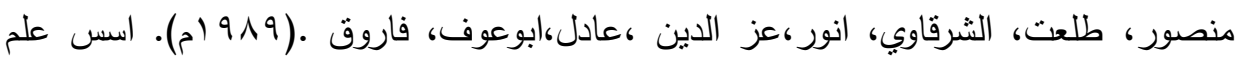
النفس العام ، القاهرة. مكتبة الانجلو المصرية.

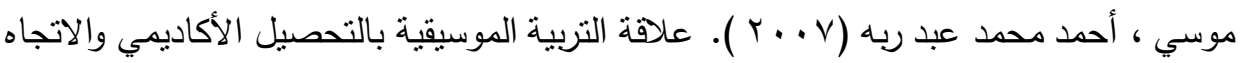
نحوها لدى طلبة المرحلة الأساسية في مدارس محافظه نابلس • رسالة دكتوراه غير منشورة . كلية التربية، جامعة غزة. نجاتي ، محمد عثمان.(99V (9)م). علم النفس والحباة.ط | (1)، الكويت: دار القلم.

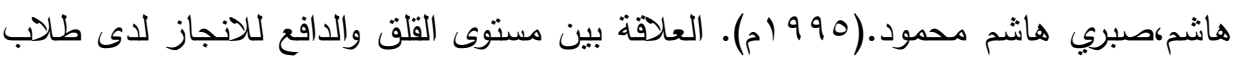
المرحلة الثانوية .رسالة ماجستير غبر منشورة، قسم الصحة النفسية، كلية التربية، جامعة الزقازيق فرع بنها.

يوسف، جمعة سيد. (1 . . rم). النظريات الحديثة في تقسير الامراض النفسية. القاهرة ك دار غريب للطباعة والنشر والنوزيع. Benjet , C \& Hernandez - Guzman , L (2001) . Gender Differences In Psychological, Well -Being Mexican Early Adolescents, Aeolescences , 36(141) . 36- Byrris , J ,

Brechting , E, Salsman , J and Carlson , C (2009) . Factors Associated With The Psychological Well- Being and Distress of University Students , Journal Of American College Health , 57(5) .

Cheng , H \& Furnham , A (2003) . Attribution Style and Self - Esteem as Predictors Of Psychological Well-Being, Counseling Psychology Quarterly , 16 (2)

Cheng , H \& Furnham (2004) . Perceived Parental Style, Self Esteem and Self - Criticism As Predictors of Happiness, Journal of Happiness Studies , 5 .

Chung , H \& gele ( 2006) . Comparing Self - Differentiation and Psychological Well-Being Between Korean and European American Students, Contemporary Family Therapy ,(28) 
علاقة قلث المستقبل بالدافع للإنجاز لاى طالبات جامعة الإمام محمد سعود الإسلامية أ/ نشمية سعود صياح الاسلامية العنزي

Kaplan,p.(1990). Educational Psychology for Tomorrows Teacher . New York $\mathrm{P}$ ublishing Company.

Macleod, A: \& Byrne,A.(1996). Anxiety , Depression:and the anticipation of future positive and Negative. 